\title{
Editorials
}

\section{Rewilding general practice}

\section{RECONNECTING WITH WHAT MATTERS}

Lyn Jenkins, a retired GP like me, and now, increasingly, taking the perspective of patients, has proposed the 'rewilding of NHS general practice. 'Answering the question 'What is rewilding?', the charity Rewilding Britain states:

restoring ecosystems to the point where nature can take care of itself, and restoring our relationship with the natural world. Reconnecting with what matters. Rewilding is hope for the future. ${ }^{2}$

In its current persecuted, demoralised, and exhausted state, ${ }^{3}$ UK general practice desperately needs hope for the future, built on a commitment to reconnecting with what matters. The ecosystems of the natural world have been profoundly destabilised by the human urge to control and exploit the environment, without first seeking to understand its substance and complexity. Rewilding challenges land management to step back from targets and rigid expectations, to resist the allure of control, to let nature find its own path, and to learn from what emerges.

\section{THE DELICATE ECOSYSTEM OF GENERAL PRACTICE}

At a smaller scale, but in very similar ways, the delicate ecosystem of general practice has been severely undermined by successive policy initiatives that have sought to control and exploit the transactions between patients and professionals without any real attempt to understand their nature or complexity. Perhaps the most potent example of this process is provided by the issue of continuity of care.

Over a lifetime of research, Barbara Starfield, together with her team at Johns Hopkins University, established that health services based on a strong system of primary healthcare produce better health

"In its current persecuted, demoralised, and exhausted state, UK general practice desperately needs hope for the future, built on a commitment to reconnecting with what matters.

outcomes at lower cost and with less health inequity. ${ }^{4}$ Such a system provides:

- first contact accessibility and use:

- identification with a regular source of care, that is, person- (rather than disease-) focused care over time;

- comprehensiveness of services available and provided; and

- coordination Iwhen care from other places is required). ${ }^{5}$

Starfield argued that the remarkable potential of primary care was mediated by the ability to integrate ongoing care around the needs of particular individuals, families, and communities rather than focusing on the standardised care of particular diseases. This ability dictates, not only thorough knowledge of the transactions of scientific medicine, but also a commitment to fostering and maintaining long-term relationships with patients: knowledge of biology must be combined with an understanding of the power of biography. Both of these matter and the delicate balance between the two represents the pre-existing natural ecosystem of general practice, which has been much valued by patients and professionals alike. Since Starfield's death in 2011, the association of continuity of care with lower mortality has been confirmed repeatedly. ${ }^{7-8}$

Yet, long before the rigours and constraints of the COVID-19 crisis, policy priorities of standardisation, bureaucratisation,

\section{long before ... the COVID-19 crisis, policy priorities of standardisation, bureaucratisation, and commodification had, gradually but inexorably, tilted the balance of primary care towards the transactional and away from the relational.}

and commodification had, gradually but inexorably, tilted the balance of primary care towards the transactional and away from the relational. This correlated with lower recruitment to general practice and lower levels of patient satisfaction. While lip service is paid to patient-centred care and shared decision making, no one in power seems ever to have understood that these require a different approach to each individual patient, informed by their predicament and their context, and that this is completely incompatible with the inflexibilities of a protocolised, standardised, and crudely incentivised system.

With the pandemic came the need to protect both patients and staff and hence the switch to virtual consultations and a drastic reduction in the ability of most practices to offer continuity of care. As is now becoming clear, it is much harder to build a trusting relationship virtually and, just when fear was everywhere, trust was falling away in the absence of faceto-face consultations. In this context, it is important to remember that little over a year ago, Matt Hancock, the then Secretary of State for Health and Social Care, insisted that all [GP] consultations should be teleconsultations' and that we mustn't 'fall back into bad old habits', but free up clinicians to concentrate on what 'really matters' labout which he had not a clue). ${ }^{9}$ Of course, it is now blindingly obvious that face-to-face consultations do really matter and Sajid Javid, Hancock's successor, is working equally clumsily to reverse what was being advocated only last year. How could any delicate ecosystem survive such a complete lack of understanding and such vacillating policy?

\section{HOPE FOR THE FUTURE}

Knowledge and understanding are essential to the success of any attempt at rewilding. Tragically, COVID-19 arrived at a point in the history of medicine when medical research was being systematically corrupted by the 


\section{"While lip service is paid to patient-centred care and shared decision making, no one in power seems ever to have understood that these require a different approach to each individual patient...}

desire to control and exploit, dictated by the economic imperatives of the medical industrial complex. The triumph of science has been the rapid creation of vaccines that have drastically reduced the risk of dying among the most vulnerable and particularly the very old. However, giving noveltechnology vaccines to healthy children, many of whom have already been infected and who are at very low risk of serious consequences, and the use of booster doses, are already mired in controversy because of the prevailing lack of transparency and the selective publication of data. Vast sums of money are at stake ${ }^{10}$ and trust in science is at a low ebb just when it is most needed. The research base of medicine appears to be yet another delicate ecosystem that has been exploited to destruction.

The concept of rewilding has the potential to forge clear links between medical research, primary healthcare, and the health of the planet. All need nurturing and protection from exploitation. All need to be underpinned by a commitment to social justice and equity. ${ }^{11}$ Further, we are witnessing an extraordinary prevalence of overdiagnosis and overtreatment, all of it futile, wasteful, and damaging to patients, and all compounded by a significant environmental impact. ${ }^{12}$

Again, these harms are driven by the desire to exploit disease for profit and it is well time that politicians and policymakers worldwide paid attention to these very serious threats to patients, the environment, and the financial viability of healthcare systems. A strong system of primary healthcare built on long-term, trusting relationships has the power to resist these repeated waves of exploitation.

So, let's rewild general practice, reconnect with the crucial relationships that really do matter, and rebuild hope for the future of us all.

\section{Iona Heath,}

Retired GP; past president of the Royal College of General Practitioners, London.

\section{Provenance}

Commissioned; externally peer reviewed.

\section{Competing interests}

The authors have declared no competing interests.

DOI: https://doi.org/10.3399/bjgp21X717689
EMAIL ADDRESS FOR CORRESPONDENCE

Iona Heath

Email: iona.heath22Ayahoo.co.uk

\section{REFERENCES}

1. Jenkins L, Esmail A, Heath I. Without action, general practice faces extinction. The Guardian 2021; 28 Sep: https://www. theguardian.com/society/2021/sep/28/ without-action-general-practice-facesextinction (accessed 3 Nov 2021).

2. Rewilding Britain. What is rewilding? https:// www.rewildingbritain.org.uk/explorerewilding/what-is-rewilding laccessed 3 Nov 2021).

3. Manek N. Stop demonising England's family doctors - we are on our knees. The Guardian 2021; 14 Oct: https://www.theguardian. com/society/2021/oct/14/stop-demonisingenglands-family-doctors-we-are-on-ourknees (accessed 3 Nov 2021).

4. Starfield B, Shi L, Macinko J. Contribution of primary care to health systems and health. Milbank Q 2005; 83(3): 457-502.

5. Starfield B. Politics, primary healthcare and health: was Virchow right? J Epidemiol Community Health 2011; 65(8): 653-655.

6. Heath I. Divided we fail. Clin Med 2011; DOI: https://doi.org/10.7861/clinmedicine.11-6-576.

7. Pereira Gray DJ, Sidaway-Lee K, White E, et al. Continuity of care with doctors - a matter of life and death? A systematic review of continuity of care and mortality. BMJ Open 2018; 8(6): e021161.

8. Sandvik $H$, Hetlevik $\emptyset$, Blinkenberg J, Hunskaar S. Continuity in general practice as predictor of mortality, acute hospitalisation, and use of out-of-hours care: a registrybased observational study in Norway. $\mathrm{Br} \mathrm{J}$ Gen Pract 2021; DOI: https://doi.org/10.3399/ BJGP.2021.0340.

9. Department of Health and Social Care, Hancock M. The future of healthcare. 2020. https://www.gov.uk/government/speeches/ the-future-of-healthcare laccessed $3 \mathrm{Nov}$ 2021).

10. Smyth J. Pfizer and Moderna forecast to almost double vaccine sales in 2022 Financial Times 2021; 18 0ct: https://www. ft.com/content/e7865240-88cc-41ba-86c23a020d1431f9 (accessed 3 Nov 2021).

11. de Barros EF, Floss M, Guinto R, et al. Planetary health care and Barbara Starfield's legacy. BMJ Global Health Blogs 2021; 10 Jun: https://blogs.bmj.com/ bmjgh/2021/06/10/planetary-health-care (accessed 3 Nov 2021).

12. Mathew R. Climate action will require radical reform of how we practise medicine. BMJ 2021; 375: n2416. 